\title{
ATMOSPHERIC CONTROLS ON EURASIAN SNOW EXTENT
}

\author{
MARTYN P. CLARK ${ }^{\mathrm{a}, *}$, MARK C. SERREZE ${ }^{\mathrm{a}}$ and DAVID A. ROBINSON ${ }^{\mathrm{b}}$ \\ a Cooperative Institute for Research in Environmental Sciences (CIRES), Division of Cryospheric and Polar Processes, \\ University of Colorado, Boulder, CO, USA \\ ${ }^{\mathrm{b}}$ Department of Geography, Rutgers University, New Brunswick, NJ, USA \\ Received 3 February 1998 \\ Revised 23 June 1998 \\ Accepted 29 June 1998
}

\begin{abstract}
Composite analyses, based on weekly snow-cover charts, temperature, sea level pressure, cyclone tracks and a rotated PCA of daily filtered $700 \mathrm{hPa}$ geopotential height are used to examine relationships between the dominant modes of low-frequency atmospheric variability and mid-winter snow extent over the Eurasian continent. Two of the circulation modes examined have been identified previously and represent the North Atlantic Oscillation (NAO) and the Eurasian Type 1 (EU1) pattern. A third, termed the Siberian pattern (SIB), has not been identified previously, and describes variability in $700 \mathrm{hPa}$ height over central Asia and southern Siberia. The most coherent snow-cover signals occur in the transient snow regions over Europe and south-western Asia, where variations in snow extent are largely controlled by temperature. Snow signals in east Asia are difficult to explain, but appear to be primarily determined by the availability of precipitation. For the NAO, snow-cover signals are largely restricted to central Europe. This result is initially surprising, as the NAO is associated with large temperature anomalies over a large part of the Eurasian continent. However, east of the Ural Mountains temperature anomalies in NAO extremes are confined to northern regions where mean temperatures are well below freezing, and air temperatures have little influence on snow extent. In extremes of the EU1 and SIB patterns, significant snow-cover signals are found in south-western Asia, where variability in the amplitude of the Eurasian wave train results in large differences in air temperature and cyclone activity over the transient snow regions. No coherent snow-cover signals are associated with extremes of the Siberian High. Copyright (C) 1999 Royal Meteorological Society.
\end{abstract}

KEY WORDS: atmospheric circulation; snow extent; principal component analysis; Eurasia; composite analyses

\section{INTRODUCTION}

The Northern Hemisphere seasonal snow-cover represents an important and highly variable component of the global climate system. Snow-cover suppresses low-level air temperatures (Lamb, 1955; Dewey, 1977; Namias, 1985; Cohen and Rind, 1991; Leathers et al., 1995; Groisman et al., 1997) through the effects of increased albedo, by inhibiting heat release from the soil, and through the energy required for warming and melting the snowpack. These effects result in increased baroclinicity at snow-cover margins, leading to a redistribution of synoptic scale storm systems (Ross and Walsh, 1986) and to changes in atmospheric circulation in the Pacific and Atlantic Ocean basins (Walsh and Ross, 1988; Barnett et al., 1989; Walland and Simmonds, 1997). In low snow years the subsequent lower levels of soil moisture have been linked to an earlier and stronger warming of the Eurasian continent, which through influencing large-scale ocean-land temperature contrasts results in an earlier and stronger Asian summer monsoon (Blanford, 1884; Walker, 1910; Hahn and Shukla, 1976; Meehl, 1994; Sankar-Rao et al., 1996).

\footnotetext{
* Correspondence to: CIRES, University of Colorado at Boulder, Campus Box 449, CO 80309-0449, USA. E-mail: clark@kryos.colorado.edu
}

Contract grant sponsor: NSF; Contract grant number: OPP-9614297; ATM-9315351; ATM-9314721; SBR-9320786

CCC 0899-8418/99/010027-14\$17.50

Copyright (C) 1999 Royal Meteorological Society 
In light of the climatic significance of Northern Hemisphere snow-cover, it is important to understand how snow-cover responds to variability in atmospheric circulation. The major modes of atmospheric variability in the Northern Hemisphere are the Pacific North American (PNA) teleconnection pattern and the North Atlantic Oscillation (NAO) (Wallace and Gutzler, 1981; Barnston and Livezey, 1987). The PNA describes an amplification/dampening of the Pacific North American wavetrain. In its positive phase it is characterized by a deep Aleutian Low, a strengthened ridge over western North America, and a strong trough over the eastern United States. These conditions inhibit cold airmasses from intruding into the western United States and deflect North Pacific storm systems northwards towards Alaska (Yarnal and Diaz, 1986; Leathers et al., 1991). The negative phase of the PNA is characterized by zonal flow over North America (and in extreme cases troughing over the western United States) (Leathers et al., 1991). The positive (negative) phase of the PNA has been shown to be associated with reduced (increased) snow-cover over western North America (Gutzler and Rosen, 1992; Brown and Goodison, 1996; Cayan, 1996; Moore and McKendry, 1996), and increased (reduced) snow-cover over the eastern United States (Serreze et al., 1998).

The NAO describes a mutual strengthening/weakening of the Icelandic Low and the Azores High. In positive extremes of this mode, the Icelandic Low and the Azores High are strong and displaced polewards (van Loon and Rogers, 1978; Rogers, 1997; Serreze et al., 1997), which leads to strong southwesterlies over northern Europe and north-western Asia with above-average temperatures in these regions (Hurrell, 1995). In negative extremes of the NAO, temperatures in these regions exhibit negative anomalies as the Icelandic Low and Azores High weaken and migrate southward, shutting off the southwesterly surface flow (Moses et al., 1987). The positive (negative) phase of the NAO is associated with decreased (increased) snow-cover over eastern North America and western Eurasia (Gutzler and Rosen, 1992).

Of the studies mentioned above, the work of Gutzler and Rosen (1992) is the only one that examines associations between atmospheric circulation and large-scale variability in snow-cover over Eurasia. The objective of the present study is to build upon Gutzler and Rosen's work by: (i) examining circulation modes other than the NAO, that may have an important influence on Eurasian snow-cover during mid winter (December through February); (ii) providing a systematic examination of the role of associated synoptic activity and temperature on midwinter snow-cover variability. To this end, a rotated principal component analysis (PCA) is performed on lowpass filtered $700 \mathrm{hPa}$ height for the region over and upstream of the Eurasian continent to identify the dominant modes of large-scale atmospheric variability. Through composite analyses, weekly changes in snow extent based on extremes of the dominant circulation modes are evaluated in conjunction with corresponding composites of $700 \mathrm{hPa}$ height, sea level pressure (SLP), air temperature, and cyclone tracks. By focusing on snow-cover change, attention is restricted, as far as possible, to the atmospheric controls on snow extent during the week long interval. As the sea level Siberian High is a dominant circulation feature of Eurasia appearing in every SLP composite, an additional examination is made of the impact of the Siberian High on snow extent.

For $700 \mathrm{hPa}$ height, SLP, temperature and cyclone tracks, we make use of National Center for Environmental Prediction/National Center for Atmospheric Research (NCEP/NCAR) 'reanalysis' fields (Kalnay et al., 1996). Snow-cover analyses rely on weekly National Oceanic and Atmospheric Administration (NOAA) snow-cover charts (Matson et al. 1986). We focus on snow extent as: (i) satellite data provide a complete areal coverage of snow extent over the Eurasian continent, contrasting with point measurements of snow depth and snow water equivalent provided by stations (sparse in some areas); (ii) although snow depth and snow water equivalent are useful variables to monitor for the snow/soil-moisture feedback at the end of the snow season, variations in snow extent are associated with variations in the regional energy balance in mid-winter (Cohen and Rind, 1991), which, in turn, may influence atmospheric circulation at remote locations (Walland and Simmonds, 1997). 


\section{DATASETS}

\subsection{Snow extent}

NOAA began mapping snow extent over Northern Hemisphere lands in 1966 (Matson et al. 1986). The weekly charts resulting from this effort comprise the longest satellite-based environmental record available. NOAA charts are produced from manual interpretation of visible satellite imagery. Snow is identified by recognizing characteristic textured surface features and brightness. The charts show snow boundaries on the last day that the surface in a given region is observed, and tend to be most representative of the fifth day of each chart week.

Charts since 1972 are considered to be sufficiently accurate for climate studies (Kukla and Robinson, 1981), particularly where: (i) skies are frequently clear, as is common in spring near the snow line; (ii) solar zenith angles are relatively small and illumination is high, which is generally the case near the snow line; (iii) the snow-cover is reasonably stable or changes slowly; and (iv) pronounced regional signatures are present owing to the distribution of vegetation, lakes and rivers. Areas of greatest difficulty for charting snow include: (i) high latitudes during autumn, when illumination is diminishing and clouds are prevalent; and (ii) the Tibetan plateau, where cover is commonly patchy and ephemeral, often resembling cloud cover.

The NOAA charts are digitized weekly using the National Meteorological Center primitive equation grid. This is an $89 \times 89$ Northern Hemisphere grid on a polar stereographic projection. Cell resolution ranges from $16000-42000 \mathrm{~km}^{2}$. Only cells interpreted to be at least $50 \%$ snow-covered are considered snow-covered. The NOAA data were obtained from the National Snow and Ice Data Center (NSIDC), University of Colorado at Boulder, where the original gridding was converted to a $25 \times 25 \mathrm{~km}$ version of the Lambert equal-area projection known as the NSIDC EASE-Grid (Armstrong and Brodzik, 1995).

\subsection{NCEP/NCAR fields}

Daily analyzed fields of $700 \mathrm{hPa}$ height and SLP and air temperature at the lowest model level $(\sigma$ level 0.995) from the NCEP/NCAR reanalysis project (Kalnay et al., 1996) are used because of their temporal consistency. Data available span the period 1958 to the present. These fields are provided on a $2.5 \times 2.5^{\circ}$ grid from the NOAA Climate Diagnostics Center (CDC) (http://www.cdc.noaa.gov/). The 6-hourly $\sigma$ level temperature, SLP and upper-air fields are designated as $A$ variables, indicating that they are strongly influenced by assimilation data (e.g. rawinsonde reports), and are hence the most reliable. However, in some areas of Eurasia (e.g. the Tibetan Plateau), available assimilation data are scanty.

Although our use of NCEP/NCAR temperatures has the advantage of providing complete and consistent coverage over Eurasia which could not be readily obtained from station data, the temperatures near the surface are influenced the model's treatment of the surface energy budget and boundary-layer mixing processes, with this influence becoming stronger as the surface is approached. Unfortunately, the NCEP reanalyses from 1973 to 1995 were inadvertently run using 1973 snow-cover for every year, meaning that air temperatures near the surface will be prone to error. While the air temperatures at the $0.995 \sigma$ level (corresponding to approximately $40 \mathrm{~m}$ above the surface) will be influenced by these errors, the effect will be less than with the $2 \mathrm{~m}$ temperatures. As our composites (described later) are constructed on the basis of circulation extremes (rather than extremes in snow extent), these errors tend to cancel. These problems should be kept in mind in the circulation/temperature discussions presented later.

\subsection{Cyclone tracks}

Cyclone tracks are used as a proxy for precipitation. This is done because daily precipitation data are difficult to come by for some European countries, contain biases in areas of blowing snow and furthermore are very sparse in some areas. The accuracy of modelled precipitation from the NCEP/ NCAR reanalysis is uncertain. Comparisons of the interannnual variability of modeled precipitation with observed data (the Global Historical Climatology Network; Eischeid et al., 1995) shows low correlations 
$(<0.5)$ through most of Asia. These differences may be due to limitations of the model, errors in precipitation measurement, or both.

The cyclone track data were obtained by passing the 6-hourly reanalysis SLP fields for the period 1958-1997 through a modified version of the cyclone detection and tracking algorithm described by Serreze (1995) and Serreze et al. (1997). This algorithm detects cyclones by inspecting whether gridpoint SLP values are surrounded by higher pressure values based on a user-specified detection threshold (taken here as $1 \mathrm{hPa}$ ) and then tracks systems using a 'nearest neighbour' analysis of cyclone positions on subsequent SLP charts. Application to the reanalysis output required that the reanalysis latitude/longitude grid be first interpolated to a $250 \mathrm{~km}$ version of the NISDC-EASE grid. The maximum distance search parameters for system tracking were also altered to be appropriate to 6-hourly output as opposed to the 12-hourly output used in earlier efforts.

\section{METHODS}

\subsection{Principal component analysis}

Associations between atmospheric circulation, snow extent and corresponding patterns of air temperature are assessed through composite analyses, using results from a rotated (Varimax) $S$-mode PCA of lowpass-filtered daily $700 \mathrm{hPa}$ geopotential height. The data utilized is for the period 1973-1995 for 235 gridpoints over the region $70^{\circ} \mathrm{W}-180^{\circ} \mathrm{E}$ and $25^{\circ}-80^{\circ} \mathrm{N}$, selecting gridpoints to provide a pseudo-equal area array (Barnston and Livezey, 1987). Gridpoints over the Himalayas were not used as $700 \mathrm{hPa}$ heights are largely fictitious in this region (Barnston and Livezey, 1987). To remove fluctuations on synoptic timescales the data were filtered using a 7-day moving average, which also provides for temporal consistency with the weekly snow charts. Separate analyses were conducted for the months of December, January, and February. A data matrix was constructed comprising the timeseries of the 235 gridpoints for each one-month window. A correlation matrix was then computed between each of the gridpoints, and PCs generated which describe coherent patterns of variance over the spatial domain.

Most of the variance for each temporal window is spread over the first ten PCs (Table I). To determine how many PCs to retain for rotation, each eigenvalue was plotted against its number, retaining the number of PCs that were above the major break in slope (Cattell, 1966). For the December and January windows, six modes were retained, and for the February window, seven were retained. In a similar analysis with 358 spatial degrees of freedom, Barnston and Livezey (1987) retained 10 modes in each of their 1-month windows. Experiments with Monte Carlo techniques (e.g. Rule- $N$ ) indicate that at least 20

Table I. Spectrum for the first ten eigenvalues

\begin{tabular}{lrrrrrrrrrr}
\hline & PC 1 & PC 2 & PC 3 & PC 4 & PC 5 & PC 6 & PC 7 & PC 8 & PC 9 & PC 10 \\
\hline December & & & & & & & & & & \\
$\quad$ Eigenvalue & 31.35 & 25.77 & 23.01 & 21.70 & 18.52 & 14.51 & 11.61 & 10.52 & 9.03 & 7.87 \\
$\quad$ Variance* & 0.13 & 0.11 & 0.10 & 0.09 & 0.08 & 0.06 & 0.05 & 0.04 & 0.04 & 0.03 \\
$\quad$ Cumulative variance* & 0.13 & 0.24 & 0.34 & 0.43 & 0.51 & 0.57 & 0.62 & 0.67 & 0.71 & 0.74 \\
January & & & & & & & & & & \\
$\quad$ Eigenvalue & 37.68 & 28.97 & 23.72 & 19.34 & 16.57 & 14.63 & 9.84 & 9.10 & 7.66 & 7.33 \\
$\quad$ Variance* & 0.16 & 0.12 & 0.10 & 0.08 & 0.07 & 0.06 & 0.04 & 0.04 & 0.03 & 0.03 \\
$\quad$ Cumulative variance* & 0.16 & 0.28 & 0.38 & 0.47 & 0.54 & 0.60 & 0.64 & 0.68 & 0.71 & 0.74 \\
February & & & & & & & & & & \\
$\quad$ Eigenvalue & 33.21 & 27.32 & 22.79 & 22.22 & 16.95 & 14.07 & 13.42 & 9.48 & 8.51 & 8.08 \\
$\quad$ Variance* & 0.14 & 0.12 & 0.10 & 0.09 & 0.07 & 0.06 & 0.06 & 0.04 & 0.04 & 0.03 \\
$\quad$ Cumulative variance* & 0.14 & 0.26 & 0.35 & 0.45 & 0.52 & 0.58 & 0.64 & 0.68 & 0.71 & 0.75 \\
\hline
\end{tabular}

* Variance described by unrotated eigenvectors. 

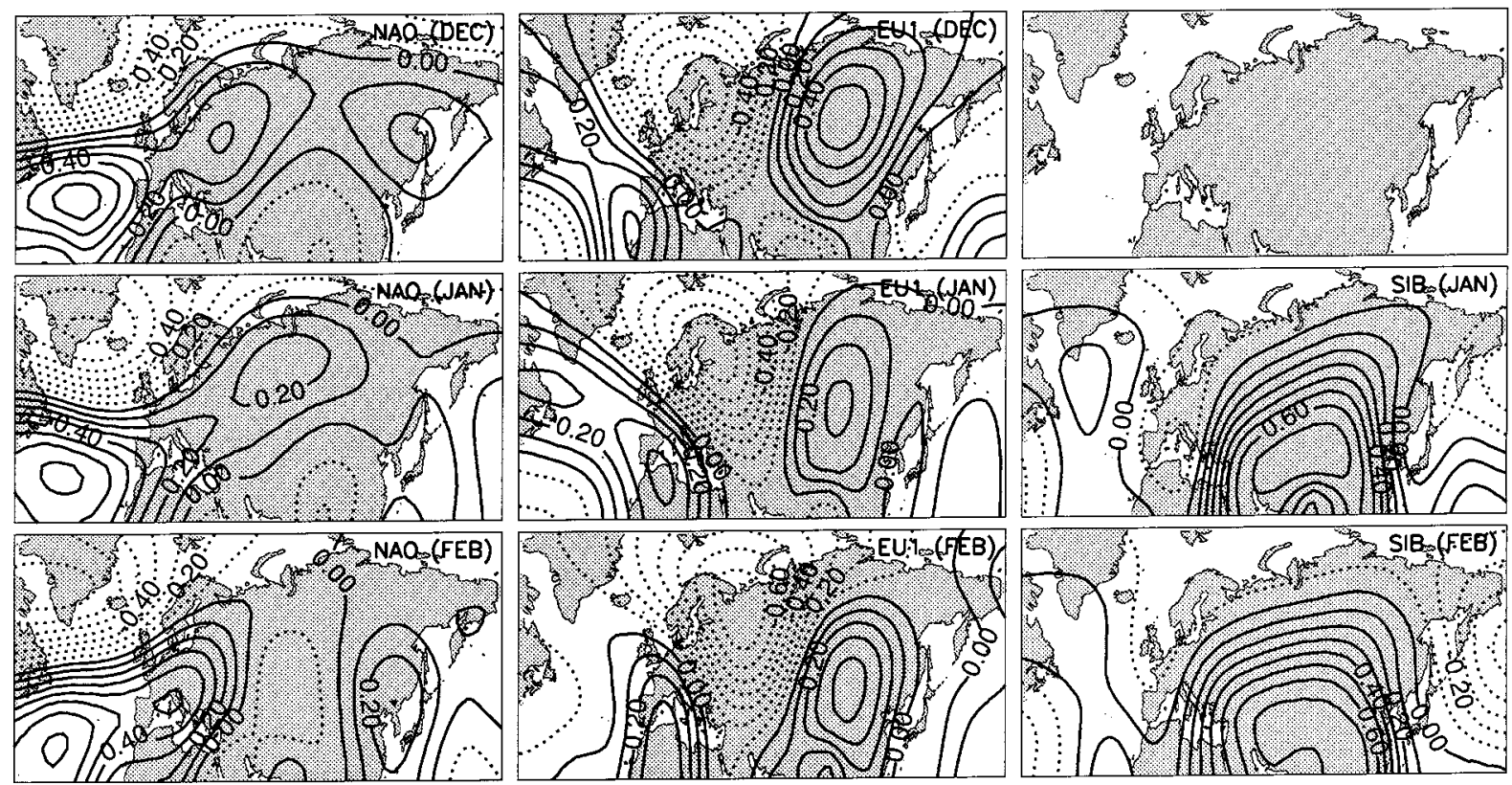

Figure 1. Spatial loading patterns from the rotated principal component analysis for the circulation modes discussed in this study. Shown are the correlation coefficients between the PC timeseries and the timeseries at each gridpoint within the spatial domain

modes should be retained, many of which have little reproducibility. However, O'Lenic and Livezey (1988) state that these techniques are rather arbitrary, and one should turn instead to sensitivity analyses. In the present study only PCs in which the major centres of action are present in at least two out of our three (independent) temporal windows are examined. 'Centres of action' are defined as subregions within the spatial domain where the spatial loading (the correlation between the time series at the gridpoints and the PC component scores) is greater than 0.35 .

Patterns examined are the North Atlantic Oscillation (NAO) and the Eurasian Type 1 (EU1) pattern (Figure 1). Both of these patterns are qualitatively similar to those identified by Barnston and Livezey (1987), and in other studies, and are discussed further in Section 5. One other pattern that examined has been termed here as the Siberian pattern (SIB). This pattern comes out in the January (PC4) and February (PC2) windows, and describes variability in $700 \mathrm{hPa}$ height over central Asia and southern Siberia. At the surface this pattern describes the strength and position of the Siberian High and therefore has similarities to the northern Asian pattern (Esbensen, 1984; Barnston and Livezey, 1987), except that it does not include the oppositely signed centre over northern Siberia. The reasons for these discrepancies are not clear, but may stem from improvements in analyzed $700 \mathrm{hPa}$ heights over southern Siberia, or from the limited size of our spatial domain. Since this mode comes out in the independent analyses conducted in January and February, the authors are confident that it describes a stable, physical mode of variability.

\subsection{Construction of the Composites}

Composites of $700 \mathrm{hPa}$ height, temperature, snow-cover, SLP and cyclone tracks are constructed using extremes of the time series of the component scores for the three patterns examined in this study. To ensure a large number of cases, cases from December, January and February were combined. Constructing the composites requires spatial aggregation of the binary (snow/no snow) data as well as a method to allow for effective comparisons between these weekly composites and composites of circulation, temperature and storm activity (based on daily data). While it is recognized that data on the weekly timescale is more noisy than for longer timescales, the finer temporal resolution is necessary to provide a sufficient number of cases for each composite. 
Table II. Number of cases in each composite

\begin{tabular}{|c|c|c|c|c|c|c|}
\hline & \multicolumn{2}{|l|}{ NAO } & \multicolumn{2}{|l|}{ EU1 } & \multicolumn{2}{|l|}{ SIB } \\
\hline & Positive & Negative & Positive & Negative & Positive & Negative \\
\hline December & 32 & 23 & 23 & 20 & - & - \\
\hline January & 27 & 23 & 29 & 30 & 21 & 26 \\
\hline February & 24 & 19 & 22 & 19 & 21 & 19 \\
\hline Total & 83 & 65 & 74 & 69 & 42 & 45 \\
\hline
\end{tabular}

To convert the binary snow-cover data to continuous values, 110 locations were specified over the Eurasian continent, for which all of the original binary pixels within a $750 \mathrm{~km}$ search radius were aggregated. Apart from a few localities near the coast, this procedure defines regions that are 1.76 million $\mathrm{km}^{2}$ in size, and include between 40 and 110 (depending on latitude) of the original snow-cover pixels. Each region overlaps such that all of the Eurasian continent is sampled. The area in each region that accumulated or lost snow between subsequent weeks was then computed, and the long term mean snow-cover change was removed from each week. Composites of weekly snow-cover change were constructed for cases where the PC component scores were $>0.75$ (positive extremes) and $<-0.75$ (negative extremes). This threshold was chosen as a compromise between the strength of the circulation signal and the number of cases in each composite. The number of cases in each composite is shown in Table II.

As discussed in Section 2, data on snow extent is most representative of the fifth day of each week. For example, for snow charts covering the weeks 1-7 December and 8-14 December, the representative dates are 5 December and 12 December, respectively. Based on this knowledge, the weekly snow-cover change is centered on day 2 of the second week ( 9 December in the above example). These mid-point dates were used to construct corresponding composites of weekly $700 \mathrm{hPa}$ height, temperature, and SLP for cases where the PC component scores were $>0.75$ and $<-0.75$. As the reanalysis fields were filtered using a 7-day running mean, each date selected is representative of atmospheric circulation throughout the week-long interval of snow-cover change. For the composites of cyclone activity, those systems which were present on one of the mid-point dates at any point in their life cycle were included. The complete track of these systems was then plotted from cyclogenesis through cyclolysis. For clarity, each track was spatially smoothed with a 5-point weighted average (1-2-3-2-1), with the smoothing applied to the latitude and longitude at each point in the track.

Weekly snow-cover changes for each PC and temporal window are also summarized for three broad regions of the Eurasian continent (Figure 2). These are defined to distinguish different large-scale climatic controls on snow extent, and cover Europe (Region 1), western Asia (Region 2) and eastern Asia (Region 3). The summaries of snow-cover change in each region (Table III) include results from significance testing, based on 2-tailed $t$-tests to determine whether the weekly snow-cover change for each PC extreme

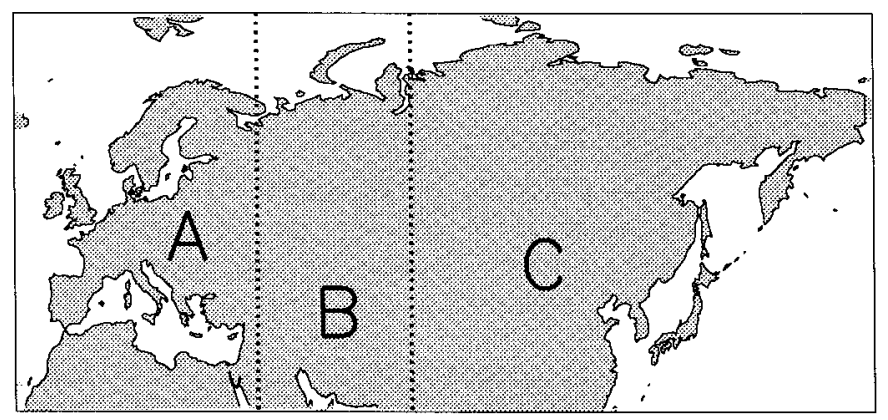

Figure 2. Delimitation of regions used in this study. (A) Region 1: 0-40 E; (B) Region 2: 40-75 ${ }^{\circ} \mathrm{E}$; (C) Region $3: 75-180^{\circ} \mathrm{E}$ 
Table III. Mean anomalous weekly snow-cover change (million $\mathrm{km}^{2}$ ) in circulation extremes

\begin{tabular}{|c|c|c|c|c|c|c|}
\hline & \multicolumn{2}{|l|}{ NAO } & \multicolumn{2}{|l|}{ EU1 } & \multicolumn{2}{|l|}{ SIB } \\
\hline & Positive & Negative & Positive & Negative & Positive & Negative \\
\hline Region 1 & -0.20 & 0.03 & 0.01 & 0.02 & -0.16 & 0.12 \\
\hline Region 2 & 0.09 & 0.02 & -0.13 & 0.12 & -0.12 & -0.02 \\
\hline Region 3 & 0.03 & -0.03 & 0.01 & -0.08 & -0.25 & -0.04 \\
\hline
\end{tabular}

Boldface, significant at $90 \%$; boldface italics, significant at $95 \%$.

and region is significantly different from the mean weekly change in that window. While it was possible to test for significance at individual gridpoints, this tended to move signals northward into regions of lower variance, and thus shifted attention away from regions of snow-cover change.

\section{GENERAL CLIMATIC FEATURES}

It is useful to start with a brief discussion of the general characteristics of snow extent, temperature and precipitation over the Eurasian continent. Snow starts accumulating in northern Siberia in October, and by December most of the Eurasian continent north of $50^{\circ} \mathrm{N}$ is snow-covered. In March, the snow-cover begins to ablate, and by May has largely disappeared. Areas of 'active' snow-cover fluctuations were identified by Frei (1997) as those where the probability of snow-cover is between 10 and $90 \%$. The areas of active snow-cover fluctuations over Eurasia for December-February (the period of maximum snow extent) defined in this manner, cover most of Europe, south-western Asia, the Tibetan Plateau, and north-eastern China (Figure 3). Winter snow depth in the continental interior averages $c a .50 \mathrm{~cm}$ with a

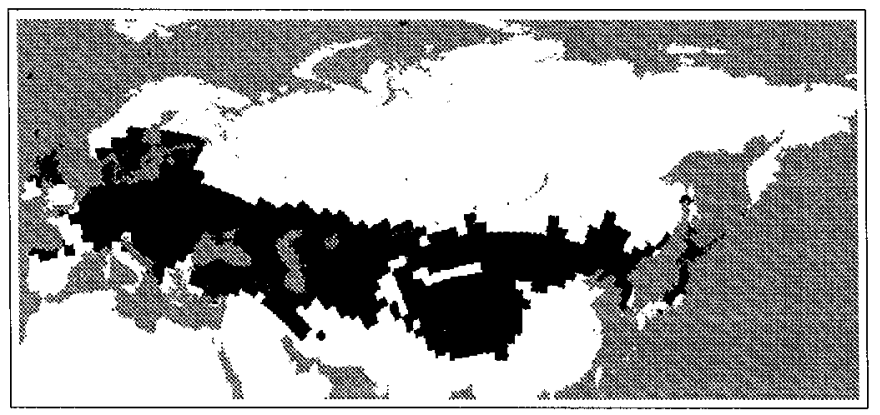

Figure 3. Areas of active snow-cover fluctuations over Eurasia during winter (December-February). Following Frei (1997), a cell was classified as 'active' if the probability of snow-cover occurence was between 10 and $90 \%$

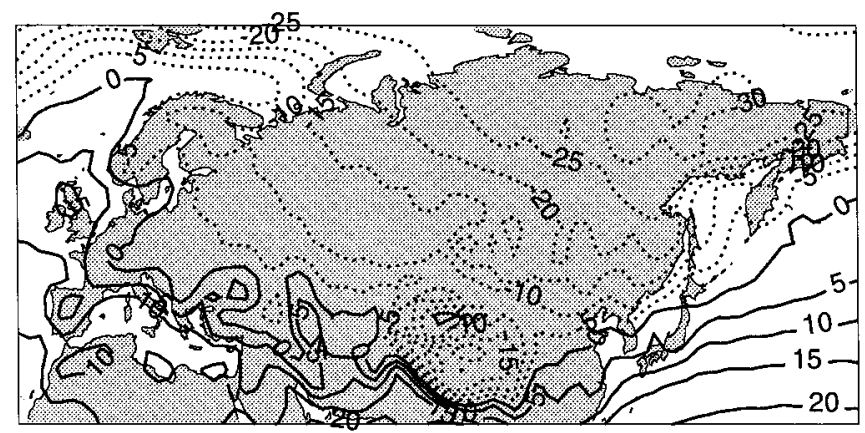

Figure 4. Mean $0.995 \sigma$ level temperatures (from NCEP/NCAR reanalysis) during winter (December-February) 
general southward decline. Precipitation over the continent is generally less than $40 \mathrm{~mm}$ per month, with amounts slightly higher in coastal margins and in central Asia (Lydolph, 1977). The mean winter 0.995 $\sigma$ level temperature field reflects the effects of continentality and latitude (Figure 4), showing air temperatures over the continental interior to be much lower than over Europe, where maritime influences are pronounced. Further details on the climatology of the former Soviet Union can be found in Lydolph (1977)

Comparisons between the mean temperature field (Figure 4) with the active snow-cover regions shown in Figure 3 reveals some interesting differences between Europe and south-western Asia, the Tibetan Plateau, and East Asia. Over Europe and south-western Asia, the active snow regions lie where mean temperatures are between 5 and $-5^{\circ} \mathrm{C}$. In these regions, air temperatures will strongly influence the persistence and melt of the snow-cover, as well as precipitation phase. Over the Tibetan plateau, the active snow regions lie where mean winter temperatures are below $-15^{\circ} \mathrm{C}$. It is reasonable to suspect that this is an artifact of the snow charting difficulties in this region (see Section 2). Basist et al. (1996) find snow-cover over the Tibetan Plateau to be present up to $20 \%$ more often in passive microwave imagery as compared with the NOAA snow charts. In eastern Asia, the active snow regions lie where mean temperatures are between -5 and $-15^{\circ} \mathrm{C}$. Here temperatures will have a more limited impact on snow extent. Since winter precipitation in East Asia is both low and infrequent (Lydolph, 1977), variability in snow extent will be primarily controlled by the availability of precipitation. Other effects such as blowing snow and penetration of solar radiation into the snowpack may be important for snow-cover change in East Asia. Groisman et al. (1994) shows that for winter (December-March) the correlation between temperature and snow extent is 0.82 over Europe and western Asia, and only 0.04 in eastern Asia. These factors should be kept in mind in the following discussion of the atmospheric controls on snow-cover.

\section{SNOW-COVER/CIRCULATION RELATIONSHIPS}

\subsection{North Atlantic Oscillation}

The North Atlantic Oscillation (NAO), which has typically been examined on the basis of SLP, describes a mutual strengthening/weakening of the Icelandic Low and the Azores High. Our SLP composites (not shown) for all windows reproduce results from previous studies (van Loon and Rogers, 1978; Rogers, 1997; Serreze et al., 1997). In positive extremes of this mode, the Icelandic Low and the Azores High are strong and displaced polewards, which leads to southwesterlies over northern Europe and north-eastern Asia with above-average temperatures in these regions. In negative extremes of the NAO, temperatures in these regions show negative temperature anomalies as the Icelandic Low and Azores High weaken and migrate southward, shutting off the southwesterly surface flow.

Our composites imply that at $700 \mathrm{hPa}$, the positive mode of the NAO is associated with west to southwest winds over northern Europe and western Siberia. A broad ridge is located over North-central Asia (Figure 5(A)). Cyclones follow a well defined track through the North Atlantic, with activity largely absent over the active snow regions in Europe (Figure 5(C)). Positive temperature anomalies $\left(>2^{\circ} \mathrm{C}\right.$ ) are evident over northern Eurasia (Figure 5(E)). The negative NAO composite features a strong ridge over the north-western Atlantic with northwesterlies over much of Europe, a weak trough over eastern Europe and a ridge over eastern Asia. (Figure 5(B)). Negative temperature anomalies prevail over northern Eurasia, locally exceeding $-4^{\circ} \mathrm{C}$ (Figure $5(\mathrm{~F})$ ). Storm tracks are much more variable in this composite (Figure 5(D)), with cyclone activity more common over Europe and south-western Asia. The general southward shift in cyclone activity in negative NAO extremes has been shown previously (Rogers, 1997; Serreze et $a l ., 1997)$ and is associated with increased precipitation over Europe (Hurrell, 1995).

In positive NAO extremes (Figure 6(A)) significant negative snow signals are found over the transient snow regions of central Europe, where mean temperatures are close to the freezing point $\left(0\right.$ to $\left.-5^{\circ} \mathrm{C}\right)$ (Figure 6(A); Table III). The straightforward interpretation is that the southwesterly flow under positive NAO extremes and associated higher temperatures suppress snow-cover. The combination of higher 

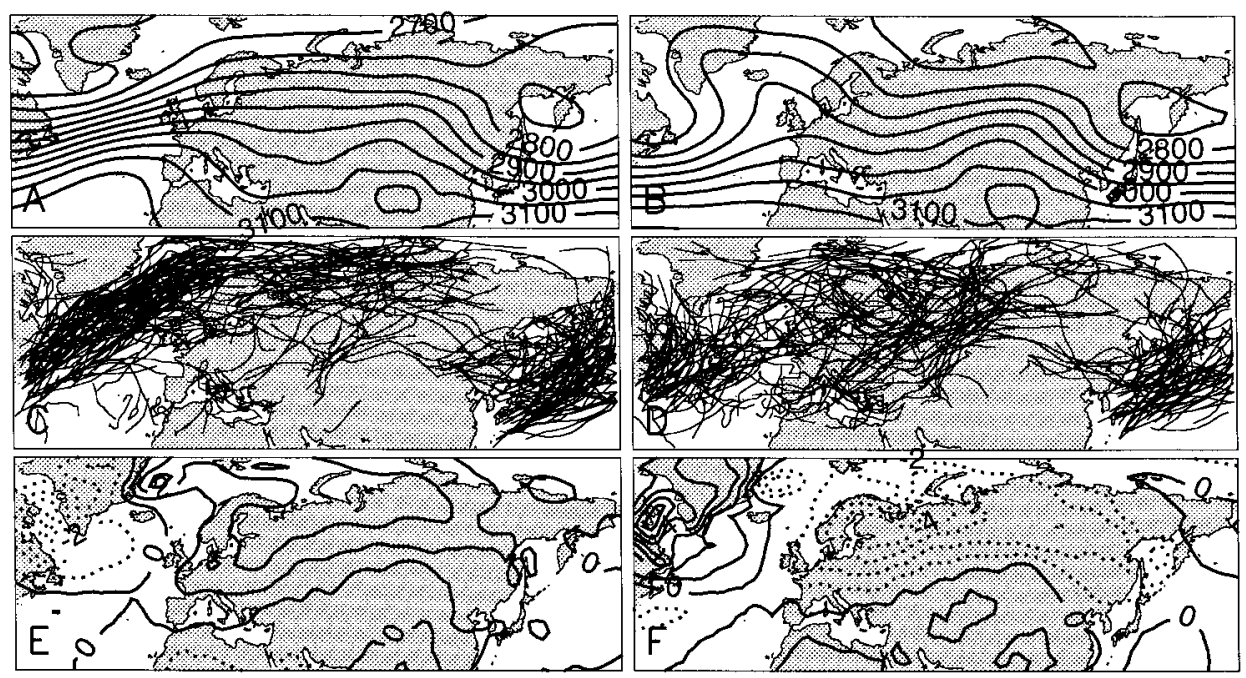

Figure 5. Climatic characteristics during NAO extremes, expressed as (A) $700 \mathrm{hPa}$ height composite for positive extremes; (B) 700 $\mathrm{hPa}$ height composite for negative extremes; (C) cyclone tracks during positive extremes; (D) cyclone tracks during negative extremes; (E) $0.995 \sigma$ level air temperature composite for positive extremes; and (F) $0.995 \sigma$ level air temperature composite for negative extremes

winter precipitation and colder conditions over most of Europe under the negative NAO mode should favour extensive snow-cover. While we do see opposing increases in snow extent in negative NAO extremes (Figure 6(B)), they are not significant (Table III). This non-linearity stems from the high variance of snow-cover in Europe under the negative NAO mode. When composites of snow-cover change were constructed with a higher threshold of the PCA factor scores, significant signals did emerge. In negative NAO extremes small increases in snow-cover are also found in south-eastern Europe (Figure 6(B)). Since temperatures in this region are close to normal, the snow-cover increases are most likely to be related to increased precipitation. While the snow-cover signals over southern Eurasia have no obvious relationship to circulation, it is noted that snow-cover data are least accurate in this region.

The significant snow-cover signals in positive NAO extremes are found well south of the region of largest temperature differences over northern Eurasia. Referring to Figure 4, these inland temperatures are low $\left(-10\right.$ to $\left.-30^{\circ} \mathrm{C}\right)$ so that even a large positive temperature anomaly will not result in melt and be observed as a change in snow extent. As this region tends to be fully snow-covered in winter (Figure 3), changes in precipitation will also have little effect on snow extent. This illustrates that although the $\mathrm{NAO}$ is a major mode of atmospheric variability influencing Eurasian temperatures, its impact on Eurasian snow extent is limited because the largest temperature anomalies occur where snow extent is insensitive to temperature.
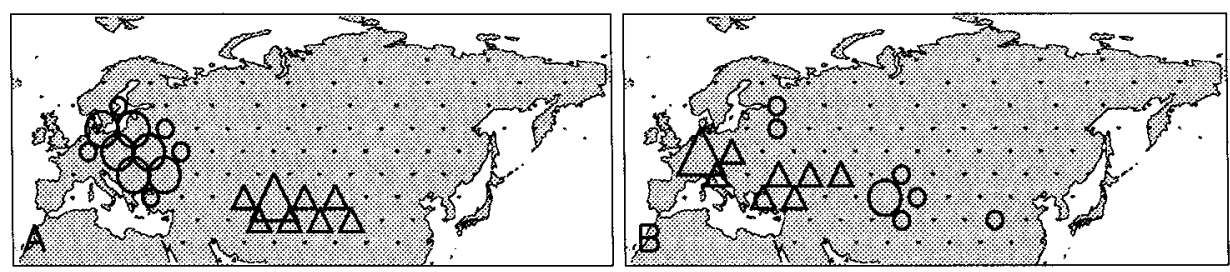

Figure 6. Composite of weekly snow-cover change for (A) positive; and (B) negative NAO extremes. Triangles indicate positive anomalies, circles indicate negative anomalies, for anomalous snow-cover change of at least $20000 \mathrm{~km}^{2}$ per week (smaller symbols) and anomalous snow-cover change of at least $40000 \mathrm{~km}^{2}$ per week (larger symbols) 

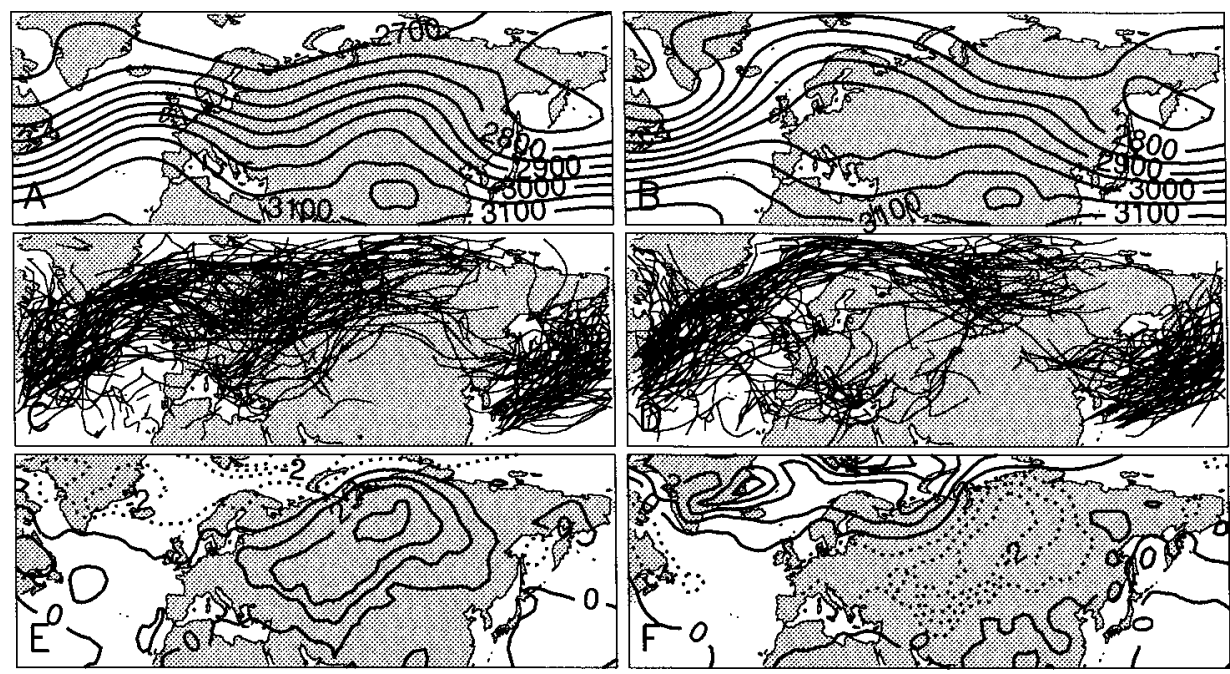

Figure 7. As Figure 5 except for the EU1 pattern

\subsection{Eurasian Type 1}

The Eurasian Type 1 (EU1) pattern is characterized by centres over northern Africa, Scandinavia, and eastern Siberia (Figure 1). Positive EU1 extremes feature a pronounced ridge over the Atlantic Ocean, a pronounced trough immediately east of the Ural mountains, followed by a strong ridge over eastern Siberia (Figure $7(\mathrm{~A})$ ). Air temperatures in positive EU1 extremes are strongly above normal $\left(>3^{\circ} \mathrm{C}\right)$ ahead of the trough over West-central Asia, with negative temperature departures $\left(1-2^{\circ} \mathrm{C}\right)$ found over the northern North Atlantic and Scandinavia where northwesterly flow prevails. Cyclone activity in positive EU1 extremes is frequent over most of Europe and West Asia. Negative EU1 extremes are associated with a strong ridge over Scandinavia (Figure 7(B)). Positive temperature anomalies $\left(>2^{\circ} \mathrm{C}\right.$ ) are found over extreme northern Europe along the crest of the ridge. Strong negative temperature anomalies occur over much of West-central Asia ahead of the ridge where northwesterlies are pronounced, locally exceeding $4^{\circ} \mathrm{C}$. Interestingly, negative anomalies of $1-2^{\circ} \mathrm{C}$ are also found in Europe, under and to the west of the ridge. This occurs due to a tendency for a cut-off low to form over Europe in $c a$. half of the cases that make up the negative EU1 composite (consistent with the positive loadings over the Mediterranean in Figure 1). In terms of cyclone activity and $700 \mathrm{hPa}$ height, negative EU1 extremes show evidence of a split flow with most cyclones being shunted northward into the Arctic Ocean (Figure 7(D)), away from the transient snow regions of Europe and south-western Asia, but with some systems tracking across southern Europe and the Mediterranean Sea. At sea level, the negative SLP composite shows a marked westward extension of the Siberian High (not shown), consistent with both the anticyclonic vorticity advection aloft and the extensive negative temperature anomalies.

The most coherent snow-cover signals associated with the EU1 pattern are found over south-western Asia, where significant decreases (increases) in snow-cover occur in positive (negative) extremes (Figure 8;
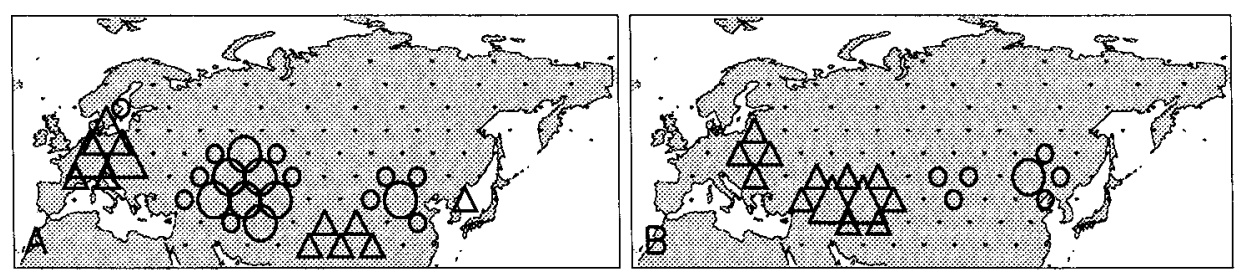

Figure 8. As Figure 6 except for the EU1 pattern 

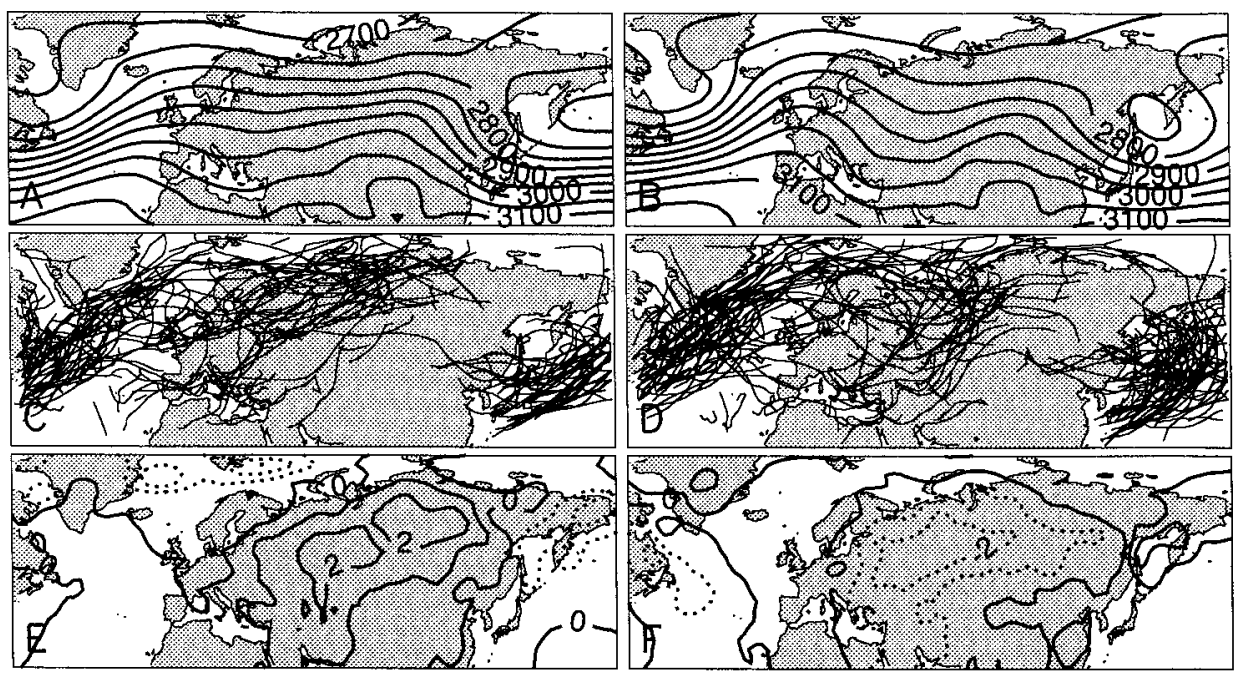

Figure 9. As Figure 5 except for the SIB pattern

Table III). The obvious control here is temperature, where the higher temperatures in positive EU1 extremes suppress snow-cover and the lower temperatures in negative extremes favour its development and persistence. Over Europe, small (insignificant) increases in snow extent are found in both positive and negative EU1 extremes (Figure 8, Table III). Although temperatures in Europe are close to normal in positive extremes, storm systems occur frequently, fostering snowfall. In negative EU1 extremes, cyclone activity is somewhat reduced over Europe. However, the small increases in snow extent lie where mean temperatures are approximately $-5^{\circ} \mathrm{C}$ (see Figure 4), implying that the precipitation that does occur will most likely fall as snow and be manifested in increases in snow extent. The small positive snow-cover signals over the Tibetan Plateau in positive EU1 extremes and the small negative signals over north-eastern China in positive and negative extremes have no obvious cause.

\subsection{Siberian Pattern}

The Siberian pattern (SIB) loads highly over southern Asia (Figure 1). Positive extremes are associated with zonal flow over much of Eurasia, but turning to northwesterlies over eastern Siberia behind the western Pacific trough (Figure 9(A)). A weak trough is found over southern Europe. Negative extremes are characterized by a strong ridge over Scandinavia, a trough roughly along the longitude of the Urals, an eastern Asian ridge, and like the positive composite, a trough over the western Pacific (Figure 9(B)). At sea level, the sharpest contrasts are in the weaker Siberian High, stronger Icelandic Low and the weaker and westward shifted Pacific Low in the negative composite. As with the other PCs, these SLP circulation contrasts are in accord with the circulation at $700 \mathrm{hPa}$. In the positive (negative) SIB composite average air temperatures are generally $2^{\circ} \mathrm{C}$ above (below) normal over western Asia.

In positive SIB extremes large negative snow-cover signals are found throughout most of Eurasia (Figure 10(A); Table III). In south-western Asia, the temperature control is clearly dominant, with the large positive temperature anomalies over the transient snow regions serving to suppress snow-cover. In
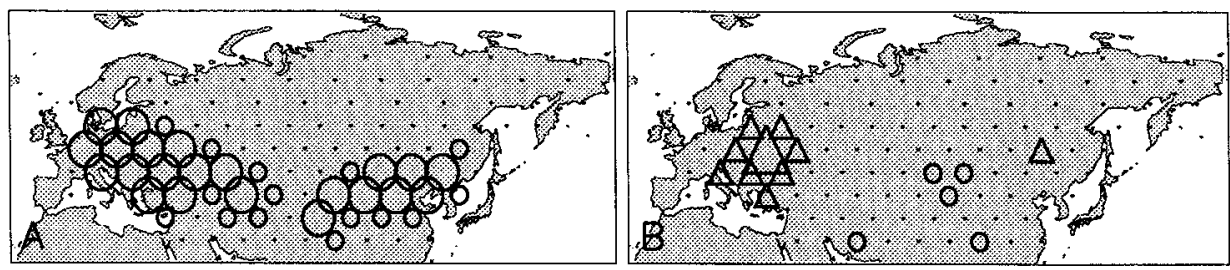

Figure 10. As Figure 6 except for the SIB pattern 
East Asia the cause of the negative snow signals are less clear, but may stem from the less frequent cyclonic activity in this area (Figure 9(C)), and an associated decrease in precipitation frequency. The strong Siberian High and the anticyclonic vorticity advection behind the East Asian trough in the positive SIB composite provides dynamical support for this argument. Recall that in East Asia snow-cover change is primarily determined by the availability of precipitation (see Section 4). Over Europe the reductions in snow extent are somewhat puzzling. Here, temperatures are close to normal, and storm systems pass through the area relatively frequently. This would lead to the expectation of little snow-cover change or even increases in snow extent.

Snow-cover changes in negative SIB extremes are characterized by significant positive signals in eastern Europe (Figure 10(B); Table III). Here, lower temperatures and a relatively frequent passage of cyclones foster snowfall. There is an absence of snow signals over south-western Asia. This is initially surprising, as this is the region of strongest temperature anomalies $\left(-1{ }^{\circ} \mathrm{C}\right.$ to $\left.-2^{\circ} \mathrm{C}\right)$. However, since the mean winter temperatures are fairly high (up to $5^{\circ} \mathrm{C}$; see Figure 4), the fairly modest temperature anomalies will have a limited impact on snow extent. Recall that in negative EU1 extremes (where temperature anomalies are up to $3^{\circ} \mathrm{C}$ below normal) there are significant snow signals in south-western Asia.

\subsection{Influence of the Siberian High}

In the preceding discussion, extensive reference to circulation at sea level was made. Since the dominant circulation feature over Eurasia in all of our SLP composites (not shown) is the Siberian High (SH), an additional examination is made of the impact of this feature on snow extent. Sahsamanoglou et al. (1991) show the SH to be most commonly located between $90-110^{\circ} \mathrm{E}$ and $40-55^{\circ} \mathrm{N}$. To examine the response of snow-cover to variations in the strength of the $\mathrm{SH}$, we developed an index of the $\mathrm{SH}$ as the area-averaged SLP over this region. The index was standardized, and composites of $700 \mathrm{hPa}$ height, air temperature, and snow-cover change were constructed in an identical manner to that used to construct composites in extremes of out PCs (i.e. composites were constructed for when the index is >0.75 S.D. above the mean (strong SH) and when the index is $<-0.75$ S.D. below the mean (weak SH)).

The $700 \mathrm{hPa}$ height composites (not shown) differ in terms of a weak trough over western Asia and a strong ridge over East Asia when the $\mathrm{SH}$ is strong, compared with a strong ridge over Scandinavia and more zonal flow over East Asia when the $\mathrm{SH}$ is weak. Air temperatures are up to $5^{\circ} \mathrm{C}$ below normal over much of eastern Asia in the strong SH composite, with air temperatures up to $3^{\circ} \mathrm{C}$ above normal in the weak $\mathrm{SH}$ composite. Little temperature change is found over Europe and West Asia in either the strong or weak SH composite. In turn, snow-cover signals in SH extremes are weak.

The lack of snow-cover signals under extremes of the SH are surprising when one considers that we do observe significant signals in the other composites (e.g. EU1 and SIB) in which the SH is variable. The reason is that upstream of the $\mathrm{SH}$ variability in airflow and hence temperature is masked when we simply composite on the strength of the high using SLP. For example, in the negative EU1 composite, northwesterly flow and the associated anticyclonic vorticity advection and low temperatures favours the development of the SH. Temperatures over western Asia are below normal, resulting in increases in snow extent (Figure 8(B)). By contrast, the ridging over eastern Asia in the positive SIB composite also favours the development of the SH. However, in this case the southwesterly flow and higher temperatures over western Asia result in decreases in snow extent (Figure 10(A)). Note that the temperature anomalies under the $\mathrm{SH}$ will have a limited impact on snow-cover.

\section{SUMMARY AND DISCUSSION}

Composite analyses, based on a rotated PCA of daily filtered $700 \mathrm{hPa}$ geopotential height over the region $70^{\circ} \mathrm{W}-180^{\circ} \mathrm{E}$ and $30^{\circ} \mathrm{N}-80^{\circ} \mathrm{N}$ are used to diagnose relationships between snow extent, circulation and temperature over the Eurasian continent during winter. Three teleconnection patterns are examined, two of which are qualitatively similar to those identified by Barnston and Livezey (1987) and other studies. These are the North Atlantic Oscillation (NAO) and the Eurasian Type 1 (EU1) patterns. One other 
pattern identified was termed the Siberian pattern (SIB), which describes variability in $700 \mathrm{hPa}$ height over central Asia and southern Siberia The most coherent snow-cover signals occur over Europe and south-western Asia, where variations in snow extent are largely controlled by temperature. The lack of the temperature control on the snow-cover variability in east Asia suggests that snow signals in this area are primarily determined by the availability of precipitation.

In positive NAO extremes, significant snow-cover signals are found in the transient snow regions over central Europe, where the southwesterly flow and associated higher temperatures suppress snow-cover. Over south-western Asia, significant reductions (increases) in snow-cover are found in positive (negative) EU1 extremes. The temperature control here is again dominant. In positive EU1 extremes, the strong ridge over East Asia results in southwesterly flow to the west providing positive temperature anomalies of ca. $2^{\circ} \mathrm{C}$. Negative EU1 extremes are associated with a weak ridge over east Asia, northwesterly to westerly flow over south-western Asia, and temperature anomalies below $-3^{\circ} \mathrm{C}$. Given the frequent cyclone activity in both positive and negative EU1 extremes, it is apparent that temperature plays an important role in influencing precipitation phase for this sector. In positive SIB extremes, significant reductions in snow-cover are found throughout Eurasia. In south-western Asia, these signals are similar to the positive EU1 extremes, where reductions in snow extent reflect a strong ridge over east Asia, with southwesterly flow and higher temperatures. Over East Asia, snow-cover reductions in positive SIB extremes most likely stem from a reduction in cyclone activity and decreased precipitation. In negative SIB extremes, snow-cover signals are restricted to eastern Europe, where below-normal temperatures and the frequent passage of cyclones results in increases in snow extent. No coherent snow-cover signals are found in extremes of the Siberian High.

The NAO signals provide a good example of the contrasting significance of temperature in transient and non-transient snow regions. The NAO is a major mode of atmospheric variability over the Northern Hemisphere, and is well known to have significant impacts on Eurasian air temperatures (Hurrell, 1995). While simply on the basis of temperature, one would expect widespread negative snow-cover signals over Eurasia, they are largely limited to central Europe (Figure 6). This is because the largest temperature anomalies occur in north-western Siberia where mean temperatures are well below freezing, and hence have a limited impact on snow-cover. The EU1 and SIB patterns, by contrast, are associated with temperature anomalies in southern regions which strongly influence snow-cover.

There are a number of factors that have not been addressed in this study. First, only the months of December, January, and February (the time of maximum snow extent) were examined, and no attempt was made to examine relationships during transitional seasons. Investigation of possible seasonalities in the atmospheric controls on snow extent would provide a useful extension of this study, and may reveal additional relationships. Also, as is evident in some of the composites, fairly subtle shifts in atmospheric circulation may have large impacts on the snow-cover. The results in this paper describe general (large-scale) relationships between atmospheric circulation and snow extent, largely neglecting that the response of the snow-cover to a given atmospheric mode varies markedly on sub-regional and local scales.

\section{ACKNOWLEDGEMENTS}

This study is supported by NSF grants OPP-9614297, ATM-9315351, ATM-9314721 and SBR-9320786. The authors also acknowledge Alexander Krenke, Institute of Geography, Russian Academy of Sciences, as well as two anonymous referees for their comments.

\section{REFERENCES}

Armstrong, R.L. and Brodzik, M.J. 1995. 'An earth-gridded SSM/I data set for cryospheric studies and global change monitoring', Adv. Space Res., 16, 155-163.

Barnett, T.P., Dumenil, L., Schlese, U., Roeckner, E. and Latif, M. 1989. 'The effect of Eurasian snow-cover on regional and global climate variations', J. Atmos. Sci., 46, 661-685.

Barnston, A.G. and Livezey, R.E. 1987. 'Classification, seasonality and persistence of low frequency atmospheric circulation patterns', Mon. Wea. Rev., 115, 1083-1126.

Basist, A., Garrett, D., Ferraro, R., Grody, N. and Mitchell, K. 1996. 'A comparison between snow-cover products derived from visible and microwave satellite observations', J. Appl. Met., 35, 163-177. 
Blanford, H.F. 1884. 'On the connection of the Himilayan snowfall with dry winds and seasons of drought in India', Proc. R. Soc. Lond., 37, 3-12.

Brown, R. and Goodison, B.E. 1996. 'Interannual variability in reconstructed Canadian snow-cover, 1915-1992', J. Climate, 9, $1299-1318$.

Cattell, R.B. 1966. 'The scree test for the number of factors', Multivar. Behav. Res., 1, 245-276.

Cayan, D.R. 1996. 'Interannual climate variability and snowpack in the western United States', J. Climate, 9, 928-948.

Cohen, J. and Rind, D. 1991. 'The effect of snow-cover on the climate', J. Climate, 4, 689-706.

Dewey, K.F. 1977. 'Daily maximum and minimum temperature forecasts and the influence of snow-cover', Mon. Wea. Rev., 105, $1594-1597$.

Eischeid, J.K., Baker, C.B., Karl, T.R. and Diaz, H.F. 1995. 'The quality control of long-term climatological data using objective data analysis', J. Appl. Meteorol., 34, 2787-2795.

Esbensen, S.K. 1984. 'A comparison of intermonthly and interannual teleconnections in the $700 \mathrm{mb}$ geopotential height field during the Northern Hemisphere winter', Mon. Wea. Rev., 112, 2016-2032.

Frei, C. 1997. Towards a snow cover fingerprint for climate change detection. Dissertation submitted to the Graduate School, New Brunswick-Rutgers, The State University of New Jersey, USA, in partial fulfillment of the degree of Doctor of Philosophy, Graduate Program in Geography.

Groisman, P.Ya., Karl, T.R., Knight, R.W. and Stenchikov, G.L. 1994. 'Changes in snow-cover, temperature and radiative heat balance over the Northern Hemisphere', J. Climate, 7, 1633-1656.

Groisman, P.Ya., Genikhovich, E.L., Bradley, R.S. and Ilyin, B.M. 1997. 'Assessing surfaceatmosphere interactions using former Soviet Union standard meteorological network data. Part II. Cloud and snow-cover effects', J. Climate, 10, 2184-2199.

Gutzler, D.S. and Rosen, R.D. 1992. 'Interannual variability of wintertime snow-cover across the Northern Hemisphere', J. Climate, 5, $1441-1447$.

Hahn, D.G. and Shukla, J. 1976. 'An apparent relationship between Eurasian snow-cover and Indian monsoon rainfall', J. Atmos. Sci., 33, 2461-2462.

Hurrell, J.W. 1995. 'Decadal trends in the North Atlantic Oscillation: Regional temperatures and precipitation', Science, 269, 676-679.

Kalnay, E.M. et al., 1996. 'The NCEP/NCAR 40-year reanalysis project', Bull. Am. Meteorol. Soc., 77, 437-471.

Kukla, G.J. and Robinson, D.A. 1981. 'Climatic value of operational snow and ice charts', in Kukla, G., Hecht, A. and Weisnet, D. (eds), SnowWatch 1980, Glaciological Data Report GD-11, World Data Center A for Glaciology, University of Colorado, Boulder, Colorado, pp. 103-119.

Lamb, H.H. 1955. 'Two-way relationships between the snow or ice limit and 1000-500 mb thicknesses in the overlying atmosphere', Q. J. R. Meteorol. Soc., 81, 172-189.

Leathers, D.J., Yarnal, B. and Palecki, M. 1991. 'The Pacific/North American teleconnection pattern and United States climate. Part I: Regional temperature and precipitation associations', J. Climate, 4, 517-528.

Leathers, D.J., Ellis, A.W. and Robinson, D.A. 1995. 'Characteristics of temperature depressions associated with snow-cover across the northeastern United States', J. Appl. Meteorol., 34, 381-390.

Lydolph, P.E. 1977. Climates of the Soviet Union (World Survey of Climatology, Volume 7), Elsevier, 443 pp.

Matson, M., Ropelewski, C.F. and Varnadore, M.S. 1986. An atlas of satellite-derived Northern Hemisphere snowcover frequency, U.S. Department of Commerce, Washington, DC, 75 pp.

Meehl, G.A. 1994. 'Influence of the land surface in the Asian summer monsoon: External conditions versus external feedbacks', $J$. Climate, 7, 1033-1049.

Moore, R.D. and McKendry, I.G. 1996. 'Spring snowpack anomaly patterns and winter climate variability, British Columbia, Canada', Water Resour. Res., 32, 623-632.

Moses, T., Kiladas, G.N., Diaz, H.F. and Barry, R.G. 1987. 'Characteristics and frequency of reversals in mean sea level pressure in the North Atlantic sector and their relationship to long-term temperature trends', J. Climatol., 7, 13-30.

Namias, J. 1985. 'Some empirical evidence of the influence of snow-cover on temperature and precipitation', Mon. Wea. Rev., 113, $1542-1553$.

O'Lenic, E.A. and Livezey, R.E. 1988. 'Practical considerations in the use of rotated principal component analysis (RPCA) in diagnostic studies of upper-air height fields', Mon. Wea. Rev., 110, 699-706.

Rogers, J. 1997. 'North Atlantic storm track variability and its association to the North Atlantic Oscillation and climate variability of Northern Europe', J. Climate, 10, 1635-1647.

Ross, B. and Walsh, J.E. 1986. 'Synoptic-scale influences of snow-cover and sea ice', Mon. Wea. Rev., 114, 1795-1810.

Sahsamanoglou, H.S., Makrogiannis, T.J. and Kallimopoulos, P.P. 1991. 'Some aspects of the basic characteristics of the Siberian anticyclone', Int. J. Climatol., 11, 827-839.

Sankar-Rao, M., Lau, K.M. and Yang, S. 1996. 'On the relationship between Eurasian snow-cover and the Asian summer monsoon,', Int. J. Climatol., 16, 605-616.

Serreze, M.C. 1995. 'Climatological aspects of cyclone development and decay in the Arctic', Atmos. Ocean, 33, 1-23.

Serreze, M.C., Rogers, J.C., Carse, F. and Barry, R.G. 1997. 'Icelandic Low cyclone activity: Climatological features, linkages with the NAO and relationships with recent changes in the Northern Hemisphere circulation', J. Climate, 10, $453-464$.

Serreze, M.C., Clark, M.P., Robinson, D.A. and McGinnis, D.L. 1998. 'Characteristics of snowfall over the eastern half of the United States and relationships with principal modes of lowfrequency atmospheric variability', J. Climate, 11, 234-250.

van Loon, H. and Rogers, J.C. 1978. 'The seesaw in winter temperatures between Greenland and northern Europe, Part I. General description', Mon. Wea. Rev., 106, 296-310.

Walker, G.R. 1910. 'Correlations in seasonal variations of weather', Mem. India. Meteorol. Dept., 21, $22-45$.

Wallace, J.M. and Gutzler, D.F. 1981. 'Teleconnections in the geopotential height field during the Northern Hemisphere winter', Mon. Wea. Rev., 109, 784-812.

Walland, D.J. and Simmonds, I. 1997. 'Modelled atmospheric response to changes in Northern Hemisphere snow-cover', Climate Dyn., 13, 25-34.

Walsh, J.E. and Ross, B. 1988. 'Sensitivity of 30-day dynamical forecasts to snow-cover', J. Climate, 1, 739-754.

Yarnal B.M. and Diaz, H.F. 1986. 'Relationships between extremes of the Southern Oscillation and the winter climate of the Anglo-American coast', J. Climatol., 6, 197-219. 